\title{
Exploring the ability of low-level laser irradiation to reduce myonecrosis and increase Myogenin transcription after Bothrops jararacussu envenomation
}

\author{
Willians Fernando Vieira ${ }^{1,2,4,5} \cdot$ Bruno Kenzo-Kagawa $^{2}$. Lúcia Elvira Alvares ${ }^{2} \cdot$ José Carlos Cogo $^{3}$ - Vitor Baranauskas ${ }^{4}$. \\ Maria Alice da Cruz-Höfling ${ }^{1,2}$ (D)
}

Received: 6 January 2021 / Accepted: 8 April 2021 / Published online: 25 April 2021

(c) The Author(s), under exclusive licence to European Photochemistry Association,European Society for Photobiology 2021

\begin{abstract}
Envenoming caused by snakebites is a very important neglected tropical disease worldwide. The myotoxic phospholipases present in the bothropic venom disrupt the sarcolemma and compromise the mechanisms of energy production, leading to myonecrosis. Photobiomodulation therapy (PBMT) has been used as an effective tool to treat diverse cases of injuries, such as snake venom-induced myonecrosis. Based on that, the aim of this study was to analyze the effects of PBMT through lowlevel laser irradiation $(904 \mathrm{~nm})$ on the muscle regeneration after the myonecrosis induced by Bothrops jararacussu snake venom (Bjssu) injection, focusing on myogenic regulatory factors expression, such as Pax7, MyoD, and Myogenin (MyoG). Male Swiss mice (Mus musculus), 6-8-week-old, weighing $22 \pm 3 \mathrm{~g}$ were used. Single sub-lethal Bjssu dose or saline was injected into the right mice gastrocnemius muscle. At 3, 24, 48, and $72 \mathrm{~h}$ after injections, mice were submitted to PBMT treatment. When finished the periods of 48 and $72 \mathrm{~h}$, mice were euthanized and the right gastrocnemius were collected for analyses. We observed extensive inflammatory infiltrate in all the groups submitted to Bjssu injections. PBMT was able to reduce the myonecrotic area at 48 and $72 \mathrm{~h}$ after envenomation. There was a significant increase of $M y o G$ mRNA expression at $72 \mathrm{~h}$ after venom injection. The data suggest that beyond the protective effect promoted by PBMT against Bjssu-induced myonecrosis, the low-level laser irradiation was able to stimulate the satellite cells, thus enhancing the muscle repair by improving myogenic differentiation.
\end{abstract}

Keywords Myonecrosis · PBMT · Snake venom - Bothrops jararacussu $\cdot$ Myogenic factors · Photobiomodulation · Satellite cell differentiation

Vitor Baranauskas: Deceased.

Maria Alice da Cruz-Höfling

hofling@unicamp.br

1 Present Address: Department of Structural and Functional Biology, Institute of Biology, University of Campinas (UNICAMP), Rua Monteiro Lobato 255, Campinas, SP 13083-970, Brazil

2 Department of Biochemistry and Tissue Biology, Institute of Biology, University of Campinas (UNICAMP), Campinas, SP, Brazil

3 Faculty of Biomedical Engineering, Brazil University, Itaquera - São Paulo, SP, Brazil

4 Department of Semiconductors, Instruments and Photonics, Faculty of Electrical Engineering, University of Campinas (UNICAMP), Campinas, SP, Brazil

5 Present Address: Department of Anatomy, Institute of Biomedical Sciences, University of São Paulo (USP), São Paulo, SP, Brazil

\section{Introduction}

Accidents caused by snakebites may cause serious or fatal envenoming in humans and are hence considered by the World Health Organization (WHO) as one of the most important neglected tropical diseases in epidemiological and severity terms $[1,2]$. The prevalence of snakebites in Latin America is inflicted largely by pit vipers belonging to Viperidae, subfamily Crotalinae, and species of the Bothrops genus [3, 4]. In Brazil, envenoming by ophidian accidents is a societal burden, mainly affecting workers of the deep countryside [5]. The hands, ankles, and legs are the body regions more subjected to bites of snakes, and skeletal muscle is the main tissue affected by Bothropic envenomation. At the bite site, anoxia caused by local microvasculature failure, as well as myonecrosis are fast developing settings. Bothrops jararacussu is the largest species of the Bothrops 
genus achieving $1.80 \mathrm{~m}$ in length; its capacity of inoculating a great amount of venom inflicts in victims serious morbidity and/or lethality. Two phospholipases ( $\mathrm{PLA}_{2}$ ) class II basic myotoxins, BthTx-I (K49 PLA 2 -Lys-49) and BthTx-

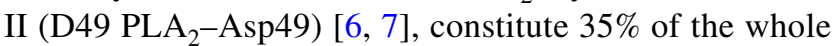
venom [8] and play a seminal role in the muscle destruction.

The $\mathrm{PLA}_{2} \mathrm{~s}$ present in the venom disrupt the cell membrane and compromise the mechanisms of energy production, the mitochondrial intermembrane ion exchange, and cellular respiration, leading to tissue necrosis [9, 10]. Recently, we have shown that the crude Bjssu and its BThTx-I and BthTx-II PLA ${ }_{2}$ myotoxins differentially inhibit the pro-myogenic regulatory factors (MRFs) expression, and activate the negative regulators of myogenesis, such as myostatin and members of ubiquitin proteasome system [11].

The use of antiophidic serum (bothropic-crotalic) is recommended in cases of bothropic envenomation, once the antivenom immunoglobulins are the only treatment available for snakebites envenoming [12]. This resource minimizes the systemic consequences of venom by modulating the inflammatory process, but neither prevent and/or reverse the myonecrosis itself $[13,14]$, nor the serum stimulates the muscle regeneration process following the installation of myonecrosis [10].

Skeletal muscle regeneration is a complex process dependent on satellite cells (muscle stem cells), which are activated upon injury and differentiate along muscle repair [15-18]. The transcription factor $\operatorname{Pax} 7$ is expressed by the satellite cells and is essential for muscle regeneration, since it coordinates the balance between self-renewal and differentiation of these cells [19]. Accordingly, $\operatorname{Pax} 7$ is known to have an anti-apoptotic effect on satellite cells, and in the absence of Pax7 expression, the cells are lost during the post-natal period, culminating in muscle atrophy and no regenerative activity [20,21]. In addition, $\operatorname{Pax} 7$ initiates the myogenic program by activating the MRFs genes, a small family of transcription factors composed by $M y o D, M y f-5$, MRF4, and MyoG (Myogenin), which coordinate different steps of the regenerative myogenesis. For instance, while $M y o D$ drives satellite cells proliferation, $M y o G$ controls the differentiation of these cells during skeletal muscle repair. Consistently, activated myoblasts express both Pax7 and $M y o D$ [22, 23]; in turn, $M y o G$ is expressed during the onset of myoblast differentiation, contributing to myofiber maturation and regulating their size [24-26].

To improve skeletal muscle regeneration, the source of treatment should regulate the inflammatory process and activate growth factors and the expression of specific factors, including Pax7 and MRFs genes. In the clinics, light in the near-infrared (NIR) spectrum $(\sim 800-950 \mathrm{~nm})$ can stimulate the regeneration of degenerated tissues, once the transmitted energy is absorbed by the cells on tissue chromophores, like the mitochondrial cytochrome $c$ oxidase (CCO). CCO functions as a photoacceptor and photosignal transducer, being the activation of ATP molecules the final critical signaling role influencing cellular metabolism [27-31]. Photobiomodulation therapy (PBMT) through lowenergy laser irradiation has been used as an effective tool to treat diverse cases of injuries, such as myonecrosis induced by snake venom [32-38]. However, little is known about the effects of PBMT on the expression of Pax7, MyoD, and $M y o G$ during the muscle regenerative process. Our hypothesis is that the effectiveness of PBMT in ameliorating the local settings caused by venomous snakebites described by the previous studies could rely on an activation of $\operatorname{Pax} 7$ and MRF genes required for muscle regeneration, differentiation, and maturation. To test this hypothesis, we analyzed the effects of PBMT through sessions of low-level laser irradiation (GaAs; $904 \mathrm{~nm}$ ) based on morphologic, morphometric and gene expression analyses at the initial steps of skeletal muscle regeneration after the installation of myonecrosis induced by Bjssu.

\section{Methods}

\subsection{Ethical statement, animals, and experimental groups}

All experiments were done in accordance to ethical guidelines of the Brazilian National Council for Animal Experimentation Control (CONCEA) and the Brazilian College of Animal Experimentation (COBEA), and were approved by the institutional Committee for Ethics in Animal Use (CEUA/UNICAMP, protocol no. 2950-1). Good laboratory practices were followed according to the international standards for animal experimentation, such as the National Institutes of Health (NIH) guides for the care and use of Laboratory animals (NIH Publications No. 8023, revised 1978), and comply with the ARRIVE guidelines. We used a total of 96 male Swiss mice (Mus musculus), 6- to 8-week-old, weighing $22 \pm 3 \mathrm{~g}$, provided by the University's Multidisciplinary Center for Biological Research (CEMIB/UNICAMP). They were randomly divided into 12 experimental groups $(8 \mathrm{spec}-$ imens per group) and maintained in standard plastic cages (5 specimens per cage) with soft bedding, receiving food and water ad libitum in a light/dark cycle (12:12 h) room with controlled temperature $\left(22^{\circ} \mathrm{C}\right)$.

\subsection{Bothrops jararacussu snake venom (Bjssu)}

Bjssu was collected from adult female snakes captured in the region of Vale do Paraíba (countryside of São Paulo State, $23^{\circ} 11^{\prime} 0^{\prime \prime} \mathrm{S} ; 45^{\circ} 53^{\prime} 0^{\prime \prime} \mathrm{W}, \mathrm{SP}$, Brazil) and kept in a serpentarium of the Vale do Paraíba University (UNIVAP), São 
José dos Campos, SP, Brazil. The venom had been harvested and certified by Dr. José Carlos Cogo (Universidade Brasil, São Paulo, SP, Brazil). Lyophilized Bjssu was maintained at $10{ }^{\circ} \mathrm{C}$ and diluted in $0.9 \%$ sterile saline solution $(\mathrm{NaCl})$ at the time of use.

\subsection{Experimental groups}

Mice were randomly divided into 12 groups. Envenomed mice from V48, VL48, VPL48, V72, VL72, and VPL72 groups received a single intramuscular (i.m.) sub-lethal dose of $830 \mu \mathrm{g} / \mathrm{kg}$ of $B j s s u$ (volume of $20 \mu \mathrm{L}$ ), which was injected into the medial portion of the right gastrocnemius muscle after skin shaving and gentle animal contention. Bjssu sublethal dose $(830 \mu \mathrm{g} / \mathrm{kg})$ was previously established by Vieira et al. [36, 38] and Kenzo-Kagawa et al. [11]. Control mice (S48, SL48, SPL48, S72, SL72, and SPL72 groups) were injected with $0.9 \%$ saline solution $(\mathrm{NaCl}$, volume of $20 \mu \mathrm{L}$, same route as for Bjssu). After 48 or $72 \mathrm{~h}$ of the injection, saline-injected, as well as the Bjssu-injected mice were euthanized under deep anesthesia with a lethal dose (i.p.) of a 3:1 mixture of ketamine chloride (Dopalen ${ }^{\circledR}, 100 \mathrm{mg} / \mathrm{kg}$ ) and xylazine chloride (Anasedan ${ }^{\circledR}, 10 \mathrm{mg} / \mathrm{kg}$ ) (Vetbrands, Jacareí, SP, Brazil) and the right gastrocnemius were collected for analyses. No medicine was given to animals.

Specific procedures for each individual group are described as follows: V48 and V72 $(n=8$ each; mice received a single i.m. injection of Bjssu and no further treatment; euthanasia was performed at 48 or $72 \mathrm{~h}$ after venom injection, respectively); VL48 and VL72 ( $\mathrm{n}=8$ each; mice received a single i.m. injection of Bjssu and were submitted to PBMT at the periods of 3,24 , and $48 \mathrm{~h}$ or $3,24,48$, and $72 \mathrm{~h}$, after the venom injection, respectively; euthanasia was performed at 48 or $72 \mathrm{~h}$, respectively); VPL48 and VPL72 ( $n=8$ each; mice received a single i.m. injection of Bjssu and were submitted to a PBMT-laser-off session at the periods of 3,24 , and $48 \mathrm{~h}$ or $3,24,48$, and $72 \mathrm{~h}$ after the venom injection, respectively; euthanasia was performed at 48 or $72 \mathrm{~h}$, respectively); $\mathbf{S 4 8}$ and $\mathbf{S 7 2}$ ( $n=8$ each; mice received a single i.m. injection of sterile saline solution, $\mathrm{NaCl} 0.9 \%$, and no treatment; euthanasia was performed at 48 or $72 \mathrm{~h}$ after saline injection, respectively); SL48 and SL72 ( $n=8$ each; mice received a single i.m. injection of saline, and were submitted to PBMT at the periods of 3,24 , and $48 \mathrm{~h}$ or $3,24,48$, and $72 \mathrm{~h}$, after saline injection, respectively; euthanasia was performed at 48 or $72 \mathrm{~h}$, respectively); SPL48 and SPL72 ( $n=8$ each; mice received a single i.m. injection of saline and were submitted to a PBMT-laser-off session at the periods of 3,24 , and $48 \mathrm{~h}$ or $3,24,48$, and $72 \mathrm{~h}$ after saline injection, respectively; euthanasia was performed at 48 or $72 \mathrm{~h}$, respectively).

\subsection{Photobiomodulation therapy (PBMT) by low-level laser irradiation}

PBMT was performed with a gallium-arsenide (GaAs) semiconductor diode laser device (BIOSET ${ }^{\circledR}$ Physiolux Dual, Rio Claro, SP, Brazil). The light was applied straight at the site of venom/saline injection, over the shaved skin, in the middle portion of the right gastrocnemius muscle. The laser probe was positioned in direct contact with the skin, at a $90^{\circ}$ angle of incidence to attenuate the reflection and minimize loss of emitted light energy. PBMT sessions occurred at 3 , 24, 48, and $72 \mathrm{~h}$ after Bjssu or saline injections, always at the same period of the day; laser parameters were chosen based on the previous studies published by our research group [36, 38], as exhibited in Table 1.

The experimental protocol is summarized in a scheme shown in Fig. 1.

\subsection{Histological analysis: morphologic and morphometric}

Samples of gastrocnemius ( $n=3$ per group) were taken by keeping the site of saline or venom injection in the middle plus $0.5 \mathrm{~cm}$ of tissue around. The selected samples were fixed in $4 \%$ paraformaldehyde (for $24 \mathrm{~h}$ ) and then routinely processed for paraffin embedding. Cross 5- $\mu \mathrm{m}$-thick sections were obtained with a Leica ${ }^{\circledR}$ rotative microtome, transferred to histological slides, and double-stained with hematoxylin and eosin (H\&E). The qualitative analysis of the gastrocnemius morphology was based on the change of muscle fibers

Table 1 Laser irradiation parameters

\begin{tabular}{llllll}
\hline Active laser & Wavelength & Medium power & Spot diameter & Delivered energy & Pulse time \\
\hline GaAs & $904 \mathrm{~nm}$ & $25 \mathrm{~W}$ & $0.2 \mathrm{~cm}$ & $2.3 \mathrm{~J}$ & $200 \mathrm{~ns}$ \\
\hline Emission mode & Power density & Energy density & Time & Laser beam & Frequency \\
\hline Pulsed & $0.196 \mathrm{~W} / \mathrm{cm}^{2}$ & $4 \mathrm{~J} / \mathrm{cm}^{2}$ & $1 \mathrm{~min} 32 \mathrm{~s}$ per session & $0.028 \mathrm{~cm}^{2}$ & $2075 \mathrm{~Hz}$ \\
\hline
\end{tabular}

Parameters were entered and automatically controlled by the equipment; PBMT cumulative energy densities per period $=3 \mathrm{~h}: 1 \mathrm{session}, 4 \mathrm{~J} / \mathrm{cm}^{2}$; $24 \mathrm{~h}: 2$ sessions, $8 \mathrm{~J} / \mathrm{cm}^{2} ; 48 \mathrm{~h}: 3$ sessions, $12 \mathrm{~J} / \mathrm{cm}^{2} ; 72 \mathrm{~h}: 4$ sessions, $16 \mathrm{~J} / \mathrm{cm}^{2}$

GaAs gallium-arsenide 


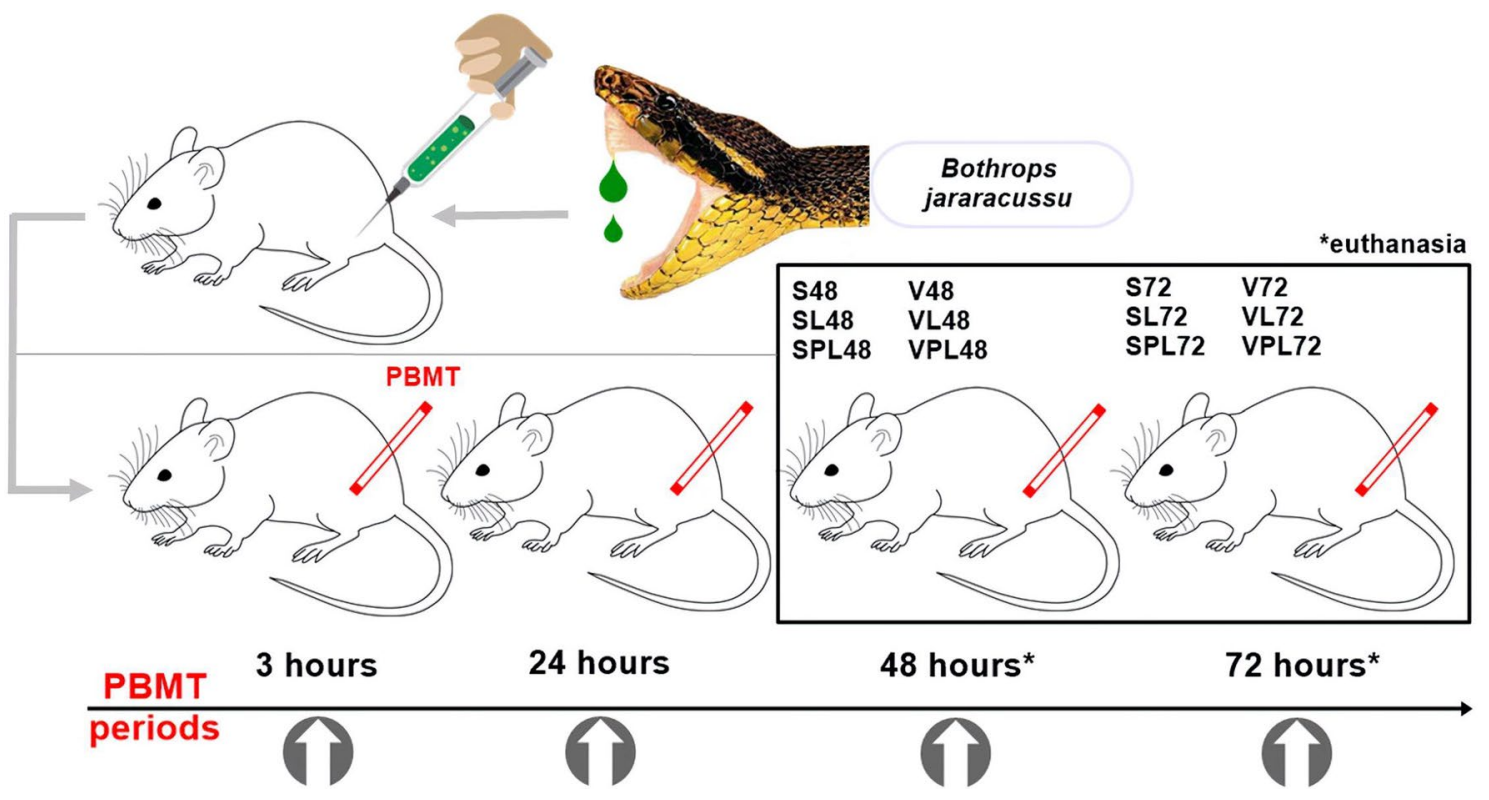

Fig. 1 Schematic representation of the experimental proposal for the study of PBMT in a murine model of envenomation by Bothrops jararacussu snake venom (Bjssu). Bjssu (represented by green drops) was harvested from adult female B. jararacussu snakes, lyophilized, diluted in saline solution $(\mathrm{NaCl} 0.9 \%)$, and injected into mice gastrocnemius muscle. At 3, 24, 48, and $72 \mathrm{~h}$ (pointed out by vertical arrows) after Bjssu or saline injections (V, venom and S, saline groups), mice were exposed to PBMT (oblique red bars, VL and

profile, pathological state, leukocyte infiltration, connective tissue status, and indistinctness of muscle fibers bundles. The slides were examined by two different examiners in an Optical Microscope Leica ${ }^{\circledR}$, with magnification images of $100 \times$. Digital images ( $n=3-4$ images/group) were captured from the three muscles per experimental group (total of 9-12 images/group) using a computer program Image-Pro Plus ${ }^{\circledR}$ software, version 4.1.1.2 for Windows 95/nt/98 1993-2001 Media Cybernetics - LB, under an optical microscope Leica DM 2500 with digital video camera Leica DFC 300FX connected to a microcomputer.

For the morphometric analysis, we considered only the Bjssu-treated groups V48, VL48, VPL48, V72, VL72, and VPL72. Three-to-four images with magnification of $10 \times$ were obtained from each histological slide, in a total of three slides per animal and 9 slides per group. After the image selection, we constructed a 300 dpi panoramic image (photomerge) by overlapping about $40 \%$ of the horizontally tilled images, with aid of the Adobe Photoshop CS6 ${ }^{\circledR}$ software. We performed the measure of the total myonecrotic area $\left(\mathrm{mm}^{2}\right)$ and the total tissue section area $\left(\mathrm{mm}^{2}\right)$, and attributed a percentage $(\%)$ of myonecrotic area with aid of the Image- ${ }^{\circledR}$ software (National Institutes of Health, Bethesda, Maryland). We considered the following calculation for the myonecrotic area:
SL groups) right at the site of the injection. VPL and SPL received venom and saline, respectively, with placebo-laser (laser-off). At 48 and $72 \mathrm{~h}$, mice were euthanized, and after gastrocnemius dissection, the envenomed area was collected and processed for histology and real-time RT-qPCR analyses. We have considered the aspects of muscle morphology (myonecrotic area) and the mRNA expression levels of $\operatorname{Pax} 7, M y o D$, and $M y o G$, which are essential to adult muscle regeneration

Total myonecrotic area $\left(\mathrm{mm}^{2}\right)$

$\frac{\text { Total tissue section area }\left(\mathrm{mm}^{2}\right)}{100}$.

\subsection{Gene expression analyses}

\subsubsection{Primers design}

Gene-specific primers for $P a x 7$, MyoD, and $M y o G$ transcription factors as well as for the housekeeping genes GAPDH (Glyceraldehyde 3-phosphate dehydrogenase) and Rps29 (Ribosomal protein S29) were designed with aid of the NCBI Primer Blast tool (https://www.ncbi.nlm.nih. gov/tools/primer-blast/). Primers sequences are shown in Table 2, as well as the GenBank accession numbers for the mouse genes used as reference to design each primer. Amplicons size was set to less than 200 base pairs to enhance PCR efficiency. Annealing temperature was set at $60{ }^{\circ} \mathrm{C}$ and the GC (guanine-cytosine) content was 50-55\%.

${ }^{\mathrm{a}}$ Housekeeping

${ }^{\mathrm{b}}$ Target genes 
Table 2 List of primers used in this study

\begin{tabular}{lll}
\hline Gene & Forward (F) and reverse (R) primers & GenBank \\
\hline Pax $^{\text {b }}$ & F: 5'-CTGGAAGTGTCCACCCCTCT-3' & NM_011039.2 \\
& R: 5'-TTGTGACGGATGTGGTTCGG-3' & \\
MyoD $^{\mathrm{b}}$ & F:5'-TACAGTGGCGACTCAGATGC-3' & NM_010866.2 \\
& R: 5'-GTAGTAGGCGGTGTCGTAGC-3' & \\
MyoG $^{\mathrm{b}}$ & F:5'-GTCCCAACCCAGGAGATC & NM_031189.2 \\
& ATTT-3' & \\
& R: 5'-TTTCGTCTGGGAAGGCAACA-3' & \\
GAPDH & F: 5'-AAGGGCTCATGACCACAGTC-3' & NM_008084.2 \\
& R: 5'-CAGGGATGATGTTCTGGGCA-3' & \\
Rps29 $^{\mathrm{a}}$ & F:5'-GGGCGTCTGAA GGCAAG & NM_009093.2 \\
& ATGGG-3' & \\
& R: 5'-TTGGAGCAGA CGCGGC & \\
AAGAG-3'
\end{tabular}

\subsubsection{RNA extraction and cDNA synthesis}

Muscle regions that were selected around Bjssu or saline site injections at the right gastrocnemius from five specimens per group were used for total RNA extraction. After dissection, muscles were fragmented and transferred to a tube containing the TRIzol ${ }^{\circledR}$ reagent $(1 \mathrm{~mL}$ per $100 \mathrm{mg}$ tissue $)$, and processed according to the manufacturer's recommendations. RNA was resuspended in $50 \mu \mathrm{L}$ of UltraPure DEPC-treated water and quantified in a NanoDrop 2000 spectrophotometer, with absorbance settled at 280/260 nm, and 260/230 nm. The integrity of RNA samples was verified by electrophoresis on $1 \%$ agarose. cDNAs were prepared with $1 \mu \mathrm{g}$ of total RNA using the RevertAid ${ }^{\mathrm{TM}} H$ Minus First-Strand cDNA Synthesis Kit. All chemicals were purchased from Thermo Fisher Scientific Inc. (Waltham, MA, USA) and the protocol was performed according to the manufacturer's recommendations.

\subsubsection{Real-time RT-qPCR}

For the RT-qPCR reactions, we used the KAPA ${ }^{\mathrm{TM}} \mathrm{SYBR}^{\circledR}$ FAST Universal qPCR 2X kit (Kapa Biosystems, Inc., Woburn, MA, USA), according to the manufacturer protocol. Each reaction was performed with $200 \mathrm{ng}$ of cDNA and $10 \mu \mathrm{M}$ of the forward and reverse primers. Reactions were prepared in MicroAmp ${ }^{\circledR}$ Fast Optical 96-Well Reaction Plates with Barcode $(0.1 \mathrm{~mL})$ (Applied Biosystems ${ }^{\circledR}$, Foster City, CA, USA). PCR cycle was set according to the following parameters: denaturation $\left(95^{\circ} \mathrm{C}, 10 \mathrm{~min}\right) ; 40$ cycles of $95{ }^{\circ} \mathrm{C}(1 \mathrm{~min}), 60{ }^{\circ} \mathrm{C}(15 \mathrm{~s})$, and $72{ }^{\circ} \mathrm{C}(20 \mathrm{~s})$; final step (final extension) of $72{ }^{\circ} \mathrm{C}(20 \mathrm{~s}), 60{ }^{\circ} \mathrm{C}(1 \mathrm{~min})$, and $95^{\circ} \mathrm{C}(15 \mathrm{~s})$. All qPCR reactions were carried out in duplicates of cDNA $(200 \mathrm{ng} / \mu \mathrm{L})$ in a StepOnePlus ${ }^{\mathrm{TM}}$ RealTime PCR System (Applied Biosystems ${ }^{\circledR}$ ). To quantify the relative expression of the target genes, we used the comparative $C_{\mathrm{t}}$ method $\left(2^{-\Delta \Delta C_{\mathrm{t}}}\right)$ [39]. The best housekeeping gene (endogenous control) was chosen based on the BestKeeper software analysis [40].

\subsection{Statistical analysis}

We applied one-way ANOVA followed by Tukey's Multiple Comparison Test for comparisons between three or more experimental groups. Student's $t$ test was used for comparisons between two groups. Statistical tests were applied using the GraphPad Prism 5.0 ${ }^{\circledR}$ (GraphPad Software Inc., San Diego, CA, USA). Data were expressed as mean \pm SEM; a $p$ value $\leq 0.05$ indicated significance.

\section{Results and discussion}

To test our hypothesis that direct light exposure to gastrocnemius of mice that had been injected with Bjssu presents the ability to modulate positively the reparative myogenic process and stimulate muscle fiber repair, we analyzed the muscle tissue at periods of 48 and $72 \mathrm{~h}$ post-envenomation. Such intervals were chosen, because in these time frames, quiescent satellite cells proliferate, differentiate, fuse, and promote the formation of new myofibers and regeneration of the functional contractile apparatus [41, 42]. We used a low-energy GaAs semiconductor diode laser operating at the NIR region of the electromagnetic spectrum (904 nm), which exhibits a deeper penetration into biological tissues than those whose emission is at the visible region of the spectrum.

\subsection{Morphologic and morphometric analyses}

S, SL, and SPL groups (48 and $72 \mathrm{~h}$ ) showed neither morphological alterations of muscle fibers nor presence of inflammatory cells. Figure 2 (panels A-F) depicts bundles of muscle fibers with their typical polygonal aspect and peripheral nuclei location. Contrariwise, it was possible to observe extensive inflammatory infiltrate in the groups V48, V72, VL48, VL72, VPL48, and VPL72 (Fig. 2, panels G-L). The placebo groups (VPL48 and VPL72) showed similar inflammatory infiltrate than V48 and V72 groups, but the pathological state of fibers was worse than that of fibers in irradiated gastrocnemius (Fig. 2, panels I and L).

Studies have shown that acute and transient inflammation represented by neutrophils and macrophages are crucial steps triggering myogenic stem cells activation aimed at repairing the damaged fibers [43, 44]. That acute inflammatory cells have positive role in the regeneration of muscle fibers damaged by Bothrops snake venoms were already demonstrated by us [45, 46]. Boeno et al. [47] also suggest that muscle repair after envenoming is a consequence of inflammasome NLRP3 (nucleotide and 


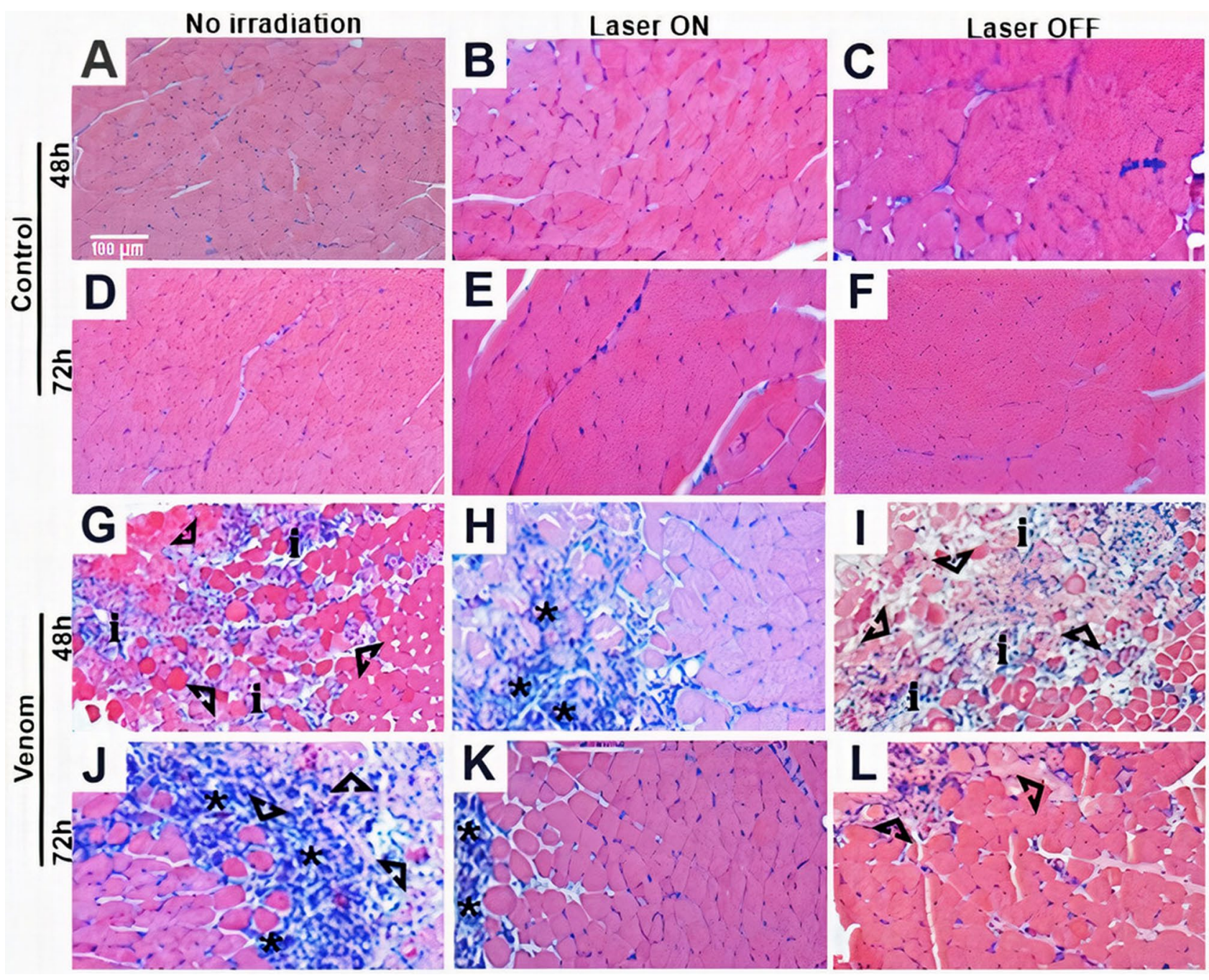

Fig. 2 Qualitative comparison of light micrographs of gastrocnemius regions of muscle of saline- and Bjssu-injected mice regarding PBMT (laser ON) or placebo (laser OFF) treatments. Saline controls (A-F) and envenomed groups $(\mathbf{G}-\mathbf{L})$, exposed or not to PBMT through low-energy laser irradiation at 3, 24, and 48 and 3, 24, 48, and $72 \mathrm{~h}$. Regardless the treatment, all saline groups are normal in morphology. Comparatively, V48 (G) and VPL48 (I) groups show greater number of myonecrotic fibers (arrowheads) intermingled amid huge inflammatory infiltrate (i) than VL48 (H), which otherwise show clusters of hematoxylin-stained myoblasts $\left(^{*}\right)$ in close contact with damaged

oligomerization domain, leucine-rich repeat-containing protein family, pyrin-containing domain 3 receptor) complex activation, once the authors observed a significant increase of Caspase- 1 and NLRP3 protein expression at $3 \mathrm{~h}$ after BthTx-I inoculation (a Lys-49 PLA 2 homologue from $B$. jararacussu venom) in mice gastrocnemius. Activated NLRP3 interacts with ASC adapter protein and procaspase-1 protein, leading to caspase- 1 activation and proinflammatory IL- $1 \beta$ protein release that contributes to the inflammatory process (for review, see Zhang et al. [48]). Our study did not contemplate the modulatory effect of fibers stained with eosin $(\mathbf{H})$. At $72 \mathrm{~h}$ after envenomation, myoblasts (*) proliferate in V72, but myonecrotic fibers persisted (arrowhead); in contrast, at the same interval, Bjssu + laser ON (VL72, K) shows a sharp border separating myoblast profuse population $(*)$ and the intact muscle fiber population, and in comparison to the non-irradiated venom group (VPL72), where damaged fibers persisted (arrowheads) and myoblasts population is rarer (L). H\&E staining; magnification images of $\times 100$; white scale bar placed in A equals to $100 \mu \mathrm{m}$, which refers to all panels

PBMT over the inflammatory mediators, but a recent study performed by Gouveia et al. [49] analyzed the protective effect of PBMT $(660 \mathrm{~nm})$ over C2C12 myoblast cells $2 \mathrm{~h}$ after exposure to different types of Bothropic venoms ( $B$. moojeni, B. jararaca, and B. jararacussu). The authors observed a high concentration of IL- $1 \beta$ and IL- 6 in the supernatant of cells previously exposed to the three different venoms and, when the PBMT was applied immediately after the venoms' incubation, a significant decrease of the pro-inflammatory cytokines was observed. Thus, the modulation of the inflammatory process seems to be an 
important effect promoted by PBMT in the initial phases of the muscle regeneration.

Herein, at 48 and $72 \mathrm{~h}$ after envenomation, it was possible to see clusters of highly basophilic myoblasts in PBMTtreated muscle (Fig. 2, panels $\mathrm{H}$ and K), whose basophilia (hematoxylin staining of ribosomes and polyribosomes) anticipates active protein synthesis to the onset of postnatal myogenesis, and which was greater than in placebotreated group (Fig. 2, panels I and L). In line, reduction of muscle fibers damage that had been caused by the BthTx-I

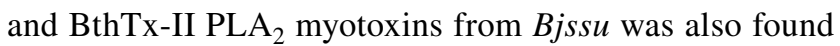
by Barbosa et al. [50] in mice gastrocnemius treated with PBMT (GaAs, $685 \mathrm{~nm}, 4.2 \mathrm{~J} / \mathrm{cm}^{2}, 29 \mathrm{~s}$ exposition, and irradiated area of $0.2 \mathrm{~cm}^{2}$ ).

To determine PBMT efficacy in counteracting Bjssu toxicity at the referred time-points, we measured the area of myonecrosis in the gastrocnemius samples. The measurements were performed only for the groups that received Bjssu injection. Hence, saline groups were not considered because of the missing necrosis. The results of myonecrotic area (\%) obtained were plotted and are shown in Fig. 3; additional data are available as Online Resource 1. Significant differences were observed when comparing V48 vs. V72 $(17.08 \pm 2.91$ vs. $7.9 \pm 0.05 ; p<0.01)$, V48 vs. VL48 (17.08 \pm 2.91 vs. $9.18 \pm 0.5 ; p<0.05)$, and V72 vs. VL72 $(7.9 \pm 0.05$ vs. $1.4 \pm 0.99 ; p<0.01)$ groups. Therefore, PBMT was able to reduce significantly the

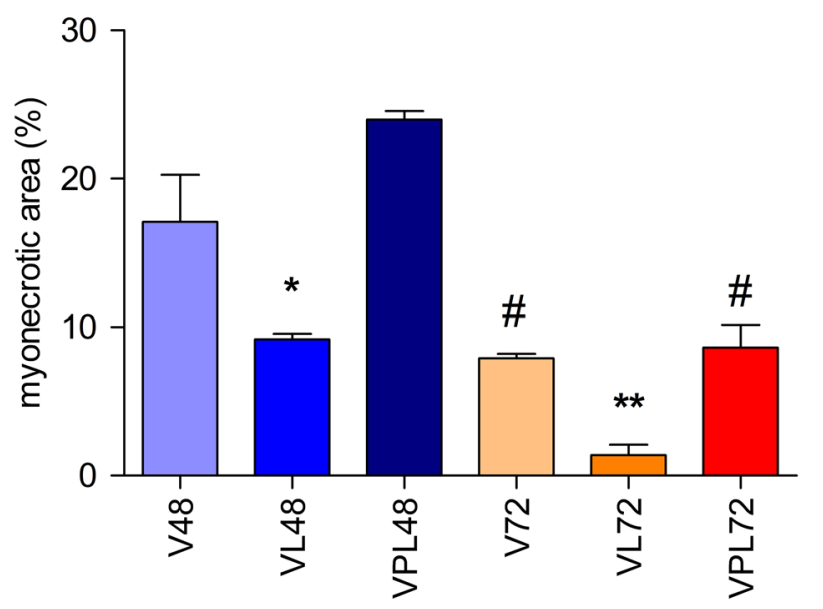

Fig. 3 Myonecrotic area (\%) of the gastrocnemius muscle from different mice groups injected with Bjssu. Measurements of myonecrotic area (\%) were performed through the relation between the total myonecrotic area $\left(\mathrm{mm}^{2}\right)$ and the total tissue section area $\left(\mathrm{mm}^{2}\right)$ plus multiplying by 100 to obtain the percentage of myonecrotic area $(\%)$. Symbols (*) and (**) mean $p<0.05$ and $p<0.01$, respectively, when irradiated groups (VL48, VL72) are different from their respective unirradiated venom groups (V48, V72); symbol (\#) means that venom groups at $72 \mathrm{~h}$ after envenoming (V72, VPL72) are different from paired at $48 \mathrm{~h}$ after envenoming (V48, VPL48). One-way ANOVA followed by Tukey's Multiple Comparison Test. Data are expressed as mean \pm SEM myonecrotic area at 48 and $72 \mathrm{~h}$ after envenomation, comparing to venom groups without laser irradiation. In addition, for the PBMT-treated groups, a significant difference $(p<0.05)$ was observed between 48 and $72 \mathrm{~h}$ (VL48 vs. VL72), i.e., the myonecrotic area reduction was directly proportional to the cumulative energy density of $16 \mathrm{~J} / \mathrm{cm}^{2}$ and energy delivered of $9.2 \mathrm{~J}$, which were achieved at $72 \mathrm{~h}$ (four PBMT sessions of $4 \mathrm{~J} / \mathrm{cm}^{2}$, i.e., at 3, 24, 48, and $72 \mathrm{~h}$; VL72 group) than the reduction obtained by $12 \mathrm{~J} / \mathrm{cm}^{2}$ and energy delivered of $6.9 \mathrm{~J}$ reached at $48 \mathrm{~h}$ (three PBMT sessions of $4 \mathrm{~J} / \mathrm{cm}^{2}$, i.e., at 3,24 , and $48 \mathrm{~h}$; VL48 group). All statistical comparisons between the groups are shown in the Appendices section.

It is important to remark that the variable time, per se, had also a curative role as shown in Fig. 2 by comparing panel $\mathrm{G}$ and $\mathrm{J}$, and herein quantitatively once there is myonecrotic area reduction in untreated groups (V48 vs. V72). In a recent similar study performed by our research group, but using Bothrops moojeni snake venom, the maximal benefit of low-energy GaAs irradiation $(904 \mathrm{~nm})$ was achieved with $12 \mathrm{~J} / \mathrm{cm}^{2}$ of energy density which was accumulated after three sessions of $4 \mathrm{~J} / \mathrm{cm}^{2}$ (unpublished data). Such difference could be basically attributable to venom proteomics content, which by their turn is influenced by snake species, their habitat, diet, age, and gender, and which together influence variability of venoms composition and toxicity [51].

Our data indicate that PBMT upgraded the repair of muscle fibers intoxicated by venom myotoxins suggesting a protective effect but likely also contribute to prevent the magnitude of damage, since PBMT started soon at $3 \mathrm{~h}$. Our morphometric analyses showed that the myonecrotic area was significantly reduced in the treated groups (VL48 and VL72) than observed in unirradiated venom groups (V48; VPL48; V72; VPL72). In this context, DoinSilva and collaborators [34] evaluated the effects of $\mathrm{HeNe}$ laser $(632.8 \mathrm{~nm}$; energy density of a single dose of 3.5 and $10.5 \mathrm{~J} / \mathrm{cm}^{2}$, or three doses of $3.5 \mathrm{~J} / \mathrm{cm}^{2}$ ) on the tibialis anterior nerve-muscle preparation of rats submitted to Bjssu injection. Nerve-muscle preparations irradiated with energy density of $3.5 \mathrm{~J} / \mathrm{cm}^{2}$ showed lesser neuromuscular blockage, reduced myonecrotic area, and lower creatinekinase (CK) serum levels than the unirradiated. These features characterize PBMT protective effects against Bjssu myotoxicity and neurotoxicity. Assis et al. [52] observed that the gallium-aluminum-arsenide (GaAlAs) diode $(808 \mathrm{~nm})$ laser was able to reduce the injured area four days after cryoinjury of the anterior tibialis muscle in a rat model, but applying a high energy density of $180 \mathrm{~J} /$ $\mathrm{cm}^{2}$. The same was observed by Brunelli et al. [53], 7 days after the treatment of cryolesioned muscle with a GaAlAs $(780 \mathrm{~nm})$ laser and doses (energy densities) of 10 and $50 \mathrm{~J} / \mathrm{cm}^{2}$. 


\subsection{Gene expression analysis}

After applying the BestKeeper analysis [40] for choosing the best housekeeping gene (endogenous control), we observed that Rps29 has shown a more stable expression among the experimental groups. Thus, the expression of the target genes was normalized by the Rps29 expression.

The paired-box transcription factor $\operatorname{Pax} 7$ and the MRF $M y o D$ have been found to have their expression induced during the satellite cell activation, before the differentiation of progenitor myogenic cells [54]. Although Pax 7 gene expression is observed both during muscle quiescence and satellite cells activation, this gene has been shown a basal level of expression once the regeneration of skeletal muscles initiates [55-57]. In agreement, in our study, we detected basal expression of Pax7 in all groups, with no significant difference among them, as shown in Fig. 4. It is likely that much of the lack of difference found herein might be consequence of high variability of the standard mean error among the groups.

There is a lack of studies about the effects of PBMT over the Pax7 expression in a model of Bothropic envenoming. Some in vitro evidence, like in the study conducted by Trajano et al. [58], has shown an increase of Pax7 expression in mouse $\mathrm{C} 2 \mathrm{C} 12$ myoblast cultures exposed to low-level infrared irradiation $\left(808 \mathrm{~nm} ; 100 \mathrm{~mW} ; 10 \mathrm{~J} / \mathrm{cm}^{2}\right)$. However, in our in vivo analyses, Pax7 expression was shown to be

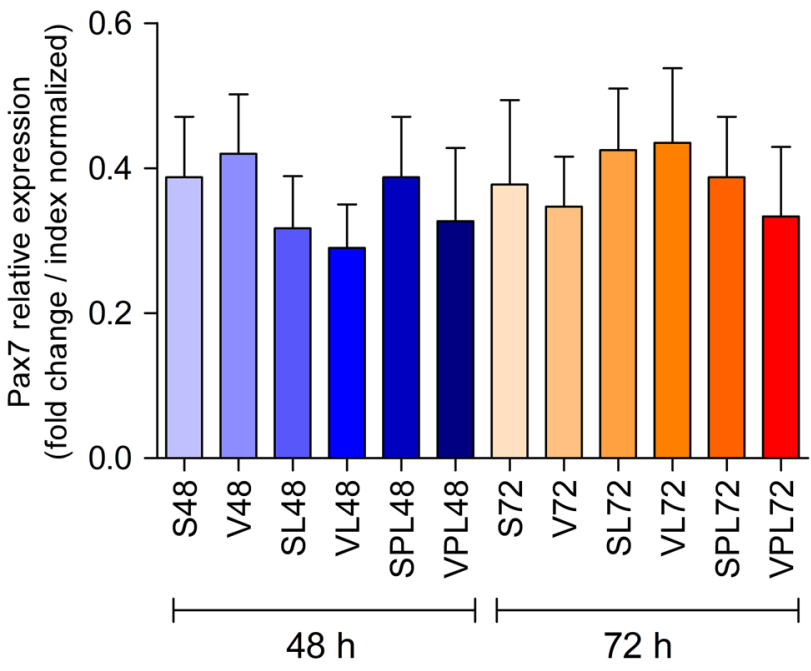

Fig. $4 \operatorname{Pax} 7$ relative gene expression levels. Real-time quantitative PCR showed no significant differences in the expression of Pax7 between the groups at 48 (S48; V48; SL48; VL48; SPL48; VPL48) and $72 \mathrm{~h}$ (S72; V72; SL72; VL72; SPL72; VPL72) post-Bjssu and post-saline injections. The target-gene ( $\operatorname{Pax} 7)$ expression was normalized by Rps 29 housekeeping expression. One-way ANOVA followed by Tukey's Multiple Comparison Test. Data are expressed as mean \pm SEM reduced, keeping its basal levels after the onset of myoblasts proliferation and differentiation [55-57, 59].

There are very few studies on gene expression modulation caused by PBMT treatment of myonecrosis induced by Bothropic envenomation. A similar study, involving the injection of crotoxin (CTX), a basic $\mathrm{PLA}_{2}$ from the venom of Crotalus durissus terrificus South American rattlesnake, in C57B 16 mice tibialis anterior muscle and daily treatment with low-level laser irradiation (1.5 J), showed an increase in $M y o D$ expression levels. In our study, there were no differences in the expression of $M y o D$ between all the experimental groups, as shown in Fig. 5. According to Grounds et al. [42], the maximum of $M y o D$ activation occurs at $24 \mathrm{~h}$ after an injury, and since our earlier observation was at $48 \mathrm{~h}$, this could be a point to help explaining our findings.

Skeletal muscle regeneration starts after chemical and/ or mechanical injury $[15,16]$, and leads to the release of cytokines, prostaglandins, nitric oxide, growth factors, and the consequent activation of satellite cells $[17,60]$. Some studies showed that PBMT treatment could stimulate those processes, for instance increasing the expression of MRFs transcripts, such as $M y o D$ and $M y o G$, which are known to play essential roles on reparative myogenesis [52, 61, 62].

Füchtbauer and Westphal [63] analyzed $M y o D$ and $M y o G$ expression in regenerating muscles after grafting and showed an upregulation within 2 weeks after injury. According to Marsh and Collaborators [64], MyoD and $M y o G$ expression increases significantly 5 days after muscle had been injured

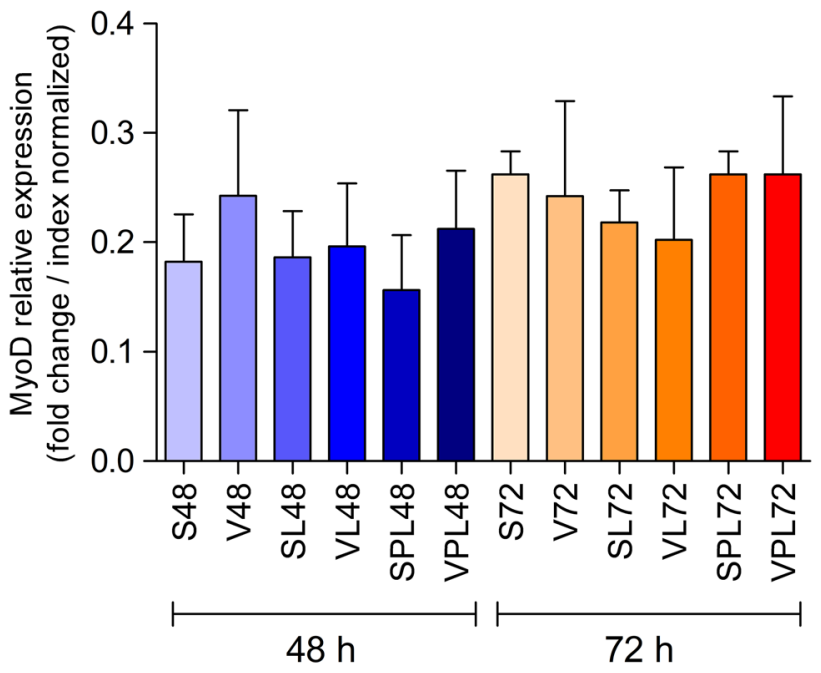

Fig. $5 M y o D$ relative gene expression levels. Real-time quantitative PCR showed no significant differences in the expression of $M y o D$ between the groups at 48 (S48; V48; SL48; VL48; SPL48; VPL48) and $72 \mathrm{~h}$ (S72; V72; SL72; VL72; SPL72; VPL72) post-Bjssu and post-saline injections. The target-gene $(M y o D)$ expression was normalized by Rps 29 housekeeping expression. One-way ANOVA followed by Tukey's multiple comparison test. Data are expressed as mean \pm SEM 
with bupivacaine injection. Those reports may explain the low expression levels of $M y o D$ in our model of study, once we analyzed gene expression at the second and third days post-injury. Performing an in vitro study, Mesquita-Ferrari et al. [65] observed no increase on $M y o D$ mRNA expression in $\mathrm{C} 2 \mathrm{C} 12$ cells exposed to laser irradiation $(780 \mathrm{~nm}$; $10 \mathrm{~mW}$; $0.2 \mathrm{~J}$ ). Performing another in vitro study, Silva et al. [66] observed an increase in MyoD and MyoG protein expressions in cultured $\mathrm{C} 2 \mathrm{C} 12$ myoblasts incubated with Bjssu during $30 \mathrm{~min} 4$ days after PBMT exposure at 685 or $830 \mathrm{~nm}\left(4.6 \mathrm{~J} / \mathrm{cm}^{2}\right)$.

In contrast to our obtained results for $M y o D$, we observed significant differences in the expression levels of $M y o G$ between the groups V72 vs. VL72 $(0.14 \pm 0.007$ vs. $1.67 \pm 0.26)(\mathrm{V} 72=0.23 \times$ vs. VL72 $=1.67 \times)$, and VL72 vs. VPL $72(1.67 \pm 0.26$ vs. $0.06 \pm 0.04)(\mathrm{VL} 72=1.67 \times$ vs. VPL72 $=0.06 \times)$, as shown in Fig. 6 . Therefore, it is thought that none difference found in relation to Pax7 and MyoD between the laser groups and laserless groups may suggest that at this specific interval, the photostimulation of satellite cells could be ruled out in this study, but not for the photostimulation of $M y o G$.

Recent study of ours showed late MyoD protein expression in mice gastrocnemius exposed to same dose of Bjssu [11]. In relation to saline sham animals, we found that the MyoD protein translation in envenomed muscle increased later at $96 \mathrm{~h}$, while MyoG increased before, at $72 \mathrm{~h}$, thus correlating herein with $M y o G$ increase and unaltered $M y o D$

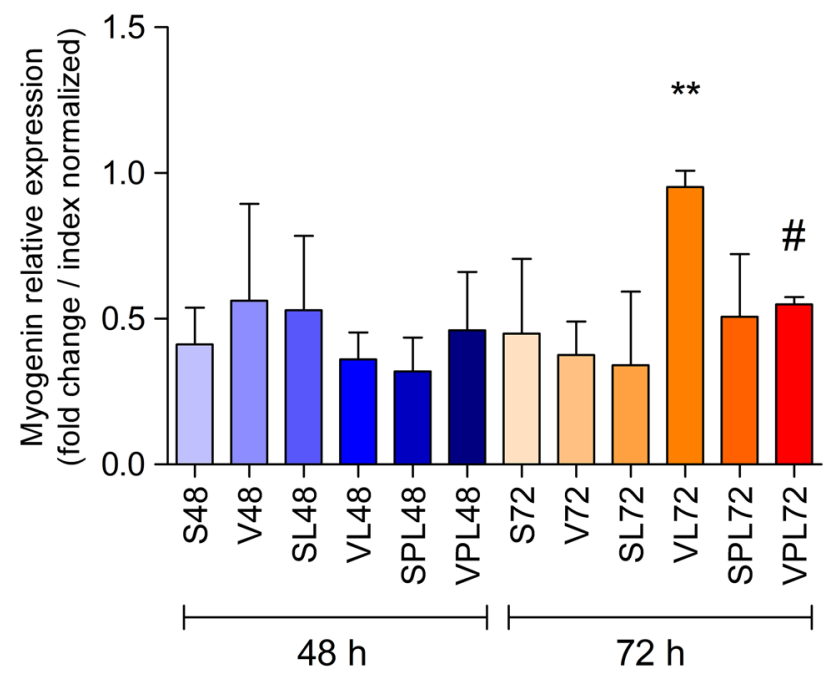

Fig. 6 MyoG relative gene expression levels. Real-time quantitative PCR showed significant differences in the expression of $M y o G$ between the groups V72 and VL72 and between V72 and VPL72. The target-gene $(M y o G)$ expression was normalized by Rps29 housekeeping expression. Symbol $(* *)$ means significant different $(p<0.01)$ from V72 group; symbol (\#) means significant different $(p<0.001)$ from VL72 group. Student's $t$ test. Data are expressed as mean \pm SEM until the $72 \mathrm{~h}$ after envenomation. In the light of referred study [11], our present findings suggest the energy generated by the photons during laser irradiation was likely unable to alter the detrimental effect of Bjssu per se. The mechanism underlying the data needs further elucidation.

During skeletal muscle repair, induction of $M y o D$ and $M y f-5$ expressions is followed by $M y o G$ and $M E F 2$ activation, which leads to the conversion of myoblasts into myotubes [67]. Thus, $M y o G$ is necessary for the terminal differentiation and its expression was improved by the PBMT at $72 \mathrm{~h}$ after Bjssu injection. The higher expression of $M y o G$ can explain the better histological aspect of the muscle fibers exposed to PBMT when comparing with that without treatment. Different results were obtained by Alves et al. [68] in a model of cryoinjury and PBMT treatment (GaAlAs; $780 \mathrm{~nm}$; $10 \mathrm{~J} / \mathrm{cm}^{2}$ ). On that study, the authors did not find differences in the MyoG mRNA expression at $72 \mathrm{~h}$ after injury. They observed a high expression of $M y o G$ mRNA only at 14 days after cryoinjury and 13 PBMT sessions (one per day). It is important to remark that results discrepancy found in the literature albeit dependent on study model can also be a consequence of inappropriate PBM parameters used; incorrect PBM parameters can promote the so-called biphasic dose response curve or the phenomenon known as hormesis, where the dose either can produce a non-significant effect or may be excessive and be inhibitory as for instance in the case of excessive exposition sessions [69]; for review, see de Freitas and Hamblin [31].

PBMT through NIR wavelength as the used here $(904 \mathrm{~nm})$ has been largely used by clinicians and in experimental animal models to treat a variety of injuries or disorders, including the related to skeletal muscle. A number of studies have recently associate muscle mitochondria and myogenesis; it is now accepted that beyond playing role in the cellular metabolism, mitochondria bioenergetics in muscle tissue are committed to regulate stem cells fate [70]. Whereas oxidative phosphorylation of such cell organelles leads to stem cells differentiation, the low aerobic metabolism and high glycolytic metabolism promote simultaneously lesser consume of oxygen, stem cell self-renewal, and so its quiescence [71].

PBM-based therapy has been grounded on heme and copper groups present in the unit IV from the respiratory chain, i.e., the mitochondrial chromophore $\mathrm{CCO}$ that absorbs light at NIR spectral region (reviewed by de Freitas and Hamblin [31] and Karu [72]. Briefly, one of the mechanisms proposed to explain the light modulation by low-level laser irradiation is based on the absorption of photons by $\mathrm{CCO}$ which then dissociates inhibitory nitric oxide (NO) from enzyme, thus promoting an increase in electron transport, mitochondrial membrane potential (MMP), and ATP production. Several signaling pathways are then triggered which result in a sequence of activations of both transcription factors and effector molecules which in turn will drive the expression 
of the genes related to cell migration, proliferation, antiinflammatory signaling, anti-apoptotic proteins, anti-oxidant enzymes, and protein synthesis [31]. Effector molecules such as HIF- $1 \alpha$ and VEGF have a prominent role in the repair of tissue damaged by snake venom myotoxins. Local hemorrhage and microvasculature failure are common events in snake envenomation that causes local hypoxic condition and coursed with muscle fibers destruction. Upon such acute hypoxic condition as a consequence of muscle perfusion failure, the local metabolism rests highly glycolytic, a condition that enables satellite cells to a state of dormancy and selfrenewal. This is a rational explanation to justify the lack of $M y o D$ expression at the usual tempo even under photostimulation. It is also reasonable to think that at $72 \mathrm{~h}$ after Bjssu exposure the angiogenic events have already taken place potentiated by four-photostimulation-session which, in turn, promotes a normoxic muscle condition propitiating mitochondrial oxidative phosphorylation and thus activation of $M y o G$ transcription at this very same $72 \mathrm{~h}$ time-point.

Studies have recently reported that beyond its prominent role in angiogenesis, VEGF, which is a direct transcriptional target of HIF-1 $\alpha$ [73], is involved in autocrine myoblast migration and survival [74]. In agreement, in a previous study, we have shown increased expression of the vascular endothelial growth factor receptor 1 (VEGF-R1) in gastrocnemius injected with Bothrops moojeni snake venom and irradiated with $\mathrm{HeNe}(632.8 \mathrm{~nm})$ or GaAs $(904 \mathrm{~nm})$. The VEGF receptor increase peaked at $3 \mathrm{~h}$ post-envenomation and remained significant upregulated at 12 and $24 \mathrm{~h}$, but stopped its expression after $72 \mathrm{~h}$. At the same time, the number of blood capillaries gradually grew peaking at the third day (72 h) after which it was stabilized [75]. It was then suggested that VEGF-R1 immunolabeling in both endothelial and non-endothelial cells, including satellite cells, likely represented a proactive VEGF mediation during the early stages of muscle regeneration (3-24 h) after B. moojeni envenoming and in parallel to microvasculature repair in response to 632.8 or $904 \mathrm{~nm}$ photostimulation [31]. VEGF ligand exerts its effects via the tyrosine kinase receptors VEGF-R1 and/ or VEGF-R2. This study gives clues about the association of VEGF ligand activation by VEGF-R1 receptor signaling corroborating the findings by Germani et al. [74] on the VEGF modulatory action on skeletal muscle myogenesis. It also allows associating possible resumed oxidative metabolism and $M y o G$ activation seen presently through PBMT.

Overall, our current results suggest that PBMT through low-energy laser irradiation at NIR spectrum likely promoted changes in satellite cells functions. This was achieved by skipping $M y o D$ inducing proliferation probably as consequence of a perfusion failure-induced high glycolytic metabolism at acute stages of envenomation but leading to differentiation as revealed by activation of $M y o G$ likely at a time at which mitochondrial oxidative metabolism had resumed.

\section{Conclusions}

PBMT was able to reducing the area of inflammatory infiltrate and improving the gene expression of $M y o G$ at $72 \mathrm{~h}$ after Bjssu injection. Besides the protective effect promoted by PBMT against myonecrosis, the low-energy laser irradiation $\left(\mathrm{GaAs} ; 904 \mathrm{~nm} ; 4 \mathrm{~J} / \mathrm{cm}^{2}\right)$ was able to stimulate the muscle regenerative process after injury. We have no grounds to firmly associate a likely early repression of oxygen consumption owing to Bjssu-induced microvasculature collapse with the lack of $M y o D$ expression (48-72 h) due to satellite cell quiescence and self-renewal. Neither have we any ground to correlate a likely second stage at which newly microvessels were rebuilt, plus mitochondrial oxidative phosphorylation is reestablished, and thereby satellite cells were activated through $\mathrm{CCO}$ photosignal triggering $M y o G$-induced differentiation. Further studies are needed to clarify the hypothesis of mitochondria bioenergetics role on this likely biphasic process of gastrocnemius reparative myogenesis, where $M y o D$ expression is repressed and $M y o G$ activation was delayed in a model of Bothropic envenomation and PBMT. A correlation of these results with blood vessel quantification and VEGF/VEGF-receptors expression throughout muscle pathogenesis is of importance to go further on PBMT pro-myogenesis role.

Supplementary Information The online version contains supplementary material available at https://doi.org/10.1007/s43630-021-00041-x.

Acknowledgements This work was supported by Grants from São Paulo Research Foundation (FAPESP) (Proc. 05/53625-1) (http:// www.fapesp.br/) and National Council for Scientific and Technological Development (CNPq, Grants \#488792/2011 and \#486142/2012-4) (http://www.cnpq.br/). MACH is an IA research fellow from CNPq (Grant \#305099/2011-6); WFV was a Master Sci. student granted with a scholarship from Coordination of Improvement of Higher Education Personnel (CAPES) (http://www.capes.gov.br/) at the Department of Semiconductors, Instruments and Photonics (FEEC-UNICAMP), and Department of Biochemistry and Tissue Biology (IB-UNICAMP). The funders had no role in study design, data collection and analysis, decision to publish, or preparation of the manuscript. We would like to thank Professor Vitor Baranauskas (Brazilian Academy of Sciences, in memoriam) by his contribution to science in the last years and for all support given for the realization of this study. Professor Baranauskas passed way in October, 2014.

Availability of data and materials The data sets generated and analyzed during the current study are available from the corresponding author (MACH; hofling@unicamp.br) upon request.

\section{Declarations}

Conflict of interest The authors have stated explicitly that there are no conflicts of interest in connection with this article.

Ethics approval All experiments were done in accordance to ethical guidelines of the Brazilian National Council for Animal Experimentation Control (CONCEA) and the Brazilian College of Animal 
Experimentation (COBEA), and were approved by the University of Campinas (UNICAMP) institutional Committee for Ethics in Animal Use (CEUA/UNICAMP, protocol no. 2950-1). Good laboratory practices were followed according to the international standards for animal experimentation, such as the National Institutes of Health (NIH) guides for the care and use of Laboratory animals (NIH Publications No. 8023, revised 1978), and comply with the ARRIVE guidelines.

\section{References}

1. Chippaux, J. P. (2017). Snakebite envenomation turns again into a neglected tropical disease! Journal of Venomous Animals and Toxins Including Tropical Diseases. https://doi.org/10.1186/ s40409-017-0127-6

2. Gutiérrez, J. M., Calvete, J. J., Habib, A. G., Harrison, R. A., Williams, D. J., \& Warrell, D. A. (2017). Snakebite envenoming. Nature Reviews Disease Primers. https://doi.org/10.1038/nrdp. 2017.63

3. Fan, H. W., \& Cardoso, J. L. (1995). Clinical toxicology of snake bites in South America. In J. Meier \& J. White (Eds.), Handbook of clinical toxicology of animal venoms and poisons. CRC Press. https://doi.org/10.1201/9780203719442

4. Gutiérrez, J. M. (1995). Clinical toxicology of snakebite in Central America. In J. Meier \& J. White (Eds.), Handbook of clinical toxicology of animal venoms and poisons. CRC Press. https://doi. org/10.1201/9780203719442

5. Schaffazick, N., Amaral, L. S., Fonseca, T. F., Tomaz, M. A., Gaban, G. A., Borges, P. A., Calil-Elias, S., Nöel, F., Melo, P. A., Quintas, L. E., \& Cunha, V. M. (2010). Effect of heparin treatment on the expression and activity of different ion-motive P-type ATPase isoforms from mouse extensor digitorum longus muscle during degeneration and regeneration after Bothrops jararacussu venom injection. Toxicon. https://doi.org/10.1016/j.toxicon.2009. 06.032

6. Hamsi-Brandeburgo, M. I., Queiroz, L. S., Santo-Neto, H., Rodrigues-Simioni, L., \& Giglio, J. R. (1988). Fractionation of Bothrops jararacussu snake venom: Partial chemical characterization and biological activity of bothropstoxin. Toxicon. https://doi.org/ 10.1016/0041-0101(88)90244-9

7. Andrião-Escarso, S. H., Soares, A. M., Rodrigues, V. M., Angulo, Y., Díaz, C., Lomonte, B., Gutiérrez, J. M., \& Giglio, J. R. (2000). Myotoxic phospholipases A(2) in bothrops snake venoms: Effect of chemical modifications on the enzymatic and pharmacological properties of bothropstoxins from Bothrops jararacussu. Biochimie. https://doi.org/10.1016/s0300-9084(00)01150-0

8. De-Simone, S. G., Napoleão-Pego, P., Teixeira-Pinto, L. A. L., Santos, J. D. L., De-Simone, T. S., Melgarejo, A. R., Aguiar, A. S., \& Marchi-Salvador, D. P. (2013). Linear B-cell epitopes in BthTX-1, BthTX-II and BthA-1, phospholipase $\mathrm{A}_{2}$ 's from Bothrops jararacussu snake venom, recognized by therapeutically neutralizing commercial horse antivenom. Toxicon. https://doi. org/10.1016/j.toxicon.2013.06.004

9. Gutiérrez, J. M., \& Lomonte, B. (1989). Local tissue damage induced by Bothrops snake venoms. A review. Memórias do Instituto Butantan, 51(4), 211-223

10. Gutiérrez, J. M., \& Ownby, C. L. (2003). Skeletal muscle degeneration induced by venom phospholipases A2: Insights into the mechanisms of local and systemic myotoxicity. Toxicon. https:// doi.org/10.1016/j.toxicon.2003.11.005

11. Kenzo-Kagawa, B., Vieira, W. F., Cogo, J. C., \& da CruzHöfling, M. A. (2020). Muscle proteolysis via ubiquitin-proteasome system (UPS) is activated by BthTx-I Lys49 PLA2 but not by BthTx-II Asp49 PLA $_{2}$ and Bothrops jararacussu venom. Toxicology and Applied Pharmacology. https://doi.org/ 10.1016/j.taap.2020.115119

12. WHO. (2010). Guidelines for the production, control and regulation of snake antivenom immunoglobulins. World Health Organization; 2010. http://www.who.int/bloodproducts/snake_ antivenoms/snakeantivenomguideline.pdf. Accessed 08 Jan 2019.

13. Brazil, V. (1911). A defesa contra o ofidismo. (p. 152). Pocai \& Weiss.

14. Rosenfeld, G. (1971). Symptomatology, pathology, and treatment of snake bites in South America, p. 345-384. In W. Bucherl, E. E. Buckley, \& V. Deulofeu (Eds.), Venomous animals and their venoms. (pp. 345-384). Academic Press.

15. Hurme, T., \& Kalimo, H. (1992). Activation of myogenic precursor cells after muscle Injury. Medicine and Science in Sports and Exercise, 24(2), 197-205 PMID: 1549008.

16. Holterman, C. E., \& Rudnicki, M. A. (2005). Molecular regulation of satellite cell function. Seminars in Cell and Developmental Biology. https://doi.org/10.1016/j.semcdb.2005.07.004

17. Filippin, L. I., Cuevas, M. J., Lima, E., Marroni, N. P., Gonzalez-Gallego, J., \& Xavier, R. M. (2011). Nitric oxide regulates the repair of injured skeletal muscle. Nitric Oxide. https://doi. org/10.1016/j.niox.2010.11.003

18. Chal, J., \& Pourquié, O. (2017). Making muscle: Skeletal myogenesis in vivo and in vitro. Development. https://doi.org/10. 1242/dev. 151035

19. Addicks, G. C., Brun, C. E., Sincennes, M.-C., Saber, J., Porter, C. J., Stewart, A. F., Ernst, P., \& Rudnicki, M. A. (2019). MLL1 is required for PAX7 expression and satellite cell selfrenewal in mice. Nature Communications. https://doi.org/10. 1038/s41467-019-12086-9

20. Relaix, F., Rocancourt, D., Mansouri, A., \& Buckingham, M. (2005). A Pax3/Pax7-dependent population of skeletal muscle progenitor cells. Nature. https://doi.org/10.1038/nature03594

21. Asfour, H. A., Allouh, M. Z., \& Said, R. S. (2018). Myogenic regulatory factors: The orchestrators of myogenesis after 30 years of discovery. Experimental Biology and Medicine. https:// doi.org/10.1177/1535370217749494

22. Hyatt, J. P., McCall, G. E., Kander, E. M., Zhong, H., Roy, R. R., \& Huey, K. A. (2008). PAX3/7 expression coincides with MyoD during chronic skeletal muscle overload. Muscle and Nerve. https://doi.org/10.1002/mus.21006

23. Wang, Y., Zhang, R. P., Zhao, Y. M., Li, Q. Q., Yan, X. P., Liu, J. Y., Gou, H., \& Li, L. (2015). Effects of Pax3 and Pax7 expression on muscle mass in the Pekin duck (Anas platyrhynchos domestica). Genetics and Molecular Research. https://doi.org/ 10.4238/2015.September.28.1

24. Hernández-Hernández, J. M., García-González, E. G., Brun, C. E., \& Rudnicki, M. A. (2017). The myogenic regulatory factors, determinants of muscle development, cell identity and regeneration. Seminars in Cell and Developmental Biology. https://doi. org/10.1016/j.semcdb.2017.11.010

25. Zammit, P. S. (2017). Function of the myogenic regulatory factors Myf5, MyoD, Myogenin and MRF4 in skeletal muscle, satellite cells and regenerative myogenesis. Seminars in Cell and Developmental Biology. https://doi.org/10.1016/j.semcdb. 2017.11.011

26. Ganassi, M., Badodi, S., Quiroga, H. P. O., Zammit, P. S., Hinits, Y., \& Hughes, S. M. (2018). Myogenin promotes myocyte fusion to balance fibre number and size. Nature Communications. https:// doi.org/10.1038/s41467-018-06583-6

27. Karu, T. I., Pyatibrat, L. V., Kolyakov, S. F., \& Afanasyeva, N. I. (2005). Absorption measurements of a cell monolayer relevant to phototherapy: Reduction of cytochrome c oxidase under near IR radiation. Journal of Photochemistry and Photobiology B: Biology. https://doi.org/10.1016/j.jphotobiol.2005.07.002 
28. Karu, T. I. (2010). Multiple roles of cytochrome $c$ oxidase in mammalian cells under action of red and IR-A radiation. IUBMB Life. https://doi.org/10.1002/iub.359

29. Mason, M. G., Nicholls, P., \& Cooper, C. E. (2010). Re-evaluation of the near infrared spectra of mitochondrial cytochrome $c$ oxidase: Implications for non-invasive in vivo monitoring of tissues. Biochimica et Biophysica Acta. https://doi.org/10.1016/j.bbabio. 2014.08.005

30. Hamblin, M. R. (2017). Mechanisms and applications of the antiinflammatory effects of photobiomodulation. AIMS Biophysics. https://doi.org/10.3934/biophy.2017.3.337

31. de Freitas, L. F., \& Hamblin, M. R. (2016). Proposed mechanisms of photobiomodulation or low-level light therapy. IEEE Journal of Selected Topics in Quantum Electronics. https://doi.org/10.1109/ JSTQE.2016.2561201

32. Dourado, D. M., Fávero, S., Baranauskas, V., \& da Cruz-Höfling, M. A. (2003). Effects of the Ga-As laser irradiation on myonecrosis caused by Bothrops moojeni snake venom. Lasers in Surgery and Medicine. https://doi.org/10.1002/lsm.10237

33. Barbosa, A. M., Villaverde, A. B., Guimarães-Souza, L., Ribeiro, W., Cogo, J. C., \& Zamunér, S. R. (2008). Effect of low-level laser therapy in the inflammatory response induced by Bothrops jararacussu snake venom. Toxicon. https://doi.org/10.1016/j.toxic on.2008.02.007

34. Doin-Silva, R., Baranauskas, V., Rodrigues-Simioni, L., \& da Cruz-Höfling, M. A. (2009). The ability of low level laser therapy to prevent muscle tissue damage induced by snake venom. Photochemistry and Photobiology. https://doi.org/10.1111/j.1751-1097. 2008.00397.x

35. Nadur-Andrade, N., Barbosa, A. M., Carlos, F. P., Lima, C. J., Cogo, J. C., \& Zamunér, S. R. (2012). Effects of photobiostimulation on edema and hemorrhage induced by Bothrops moojeni venom. Lasers in Medical Science. https://doi.org/10.1007/ s10103-011-0914-1

36. Vieira, W. F., Kenzo-Kagawa, B., Cogo, J. C., Baranauskas, V., \& da Cruz-Höfling, M. A. (2016). Low-level laser therapy (904 $\mathrm{nm})$ counteracts motor deficit of mice hind limb following skeletal muscle injury caused by snakebite-mimicking intramuscular venom injection. PLoS ONE. https://doi.org/10.1371/journal. pone. 0158980

37. Dourado, D. M., Matias, R., Barbosa-Ferreira, M., Silva, B. A. K., Muller, J. A. I., Vieira, W. F., \& da Cruz-Höfling, M. A. (2017). Effects of photobiomodulation therapy on Bothrops moojeni snake-envenomed gastrocnemius of mice using enzymatic biomarkers. Lasers in Medical Science. https://doi.org/10.1007/ s10103-017-2252-4

38. Vieira, W. F., Kenzo-Kagawa, B., Britto, M. H. M., Ceragioli, H. J., Sakane, K. K., Baranauskas, V., \& da Cruz-Höfling, M. A. (2018). Vibrational spectroscopy of muscular tissue intoxicated by snake venom and exposed to photobiomodulation therapy. Lasers in Medical Science. https://doi.org/10.1007/s10103-017-2389-1

39. Livak, K. J., \& Schmittgen, T. D. (2001). Analysis of relative gene expression data using real-time quantitative PCR and the 2(-Delta Delta $C(\mathrm{~T}))$ method. Methods. https://doi.org/10.1006/meth.2001. 1262

40. Pfaffl, M. W., Tichopad, A., Prgomet, C., \& Neuvians, T. P. (2004). Determination of stable housekeeping genes, differentially regulated target genes and sample integrity: BestKeeperEXCEL-based tool using pair-wise correlations. Biotechnology Letters. https://doi.org/10.1023/B:BILE.0000019559.84305.47

41. Allbrook, D. (1981). Skeletal muscle regeneration. Muscle and Nerve. https://doi.org/10.1002/mus.880040311

42. Grounds, M. D., Garret, K. L., Lai, M. C., Wright, W. E., \& Beilharz, M. W. (1992). Identification of skeletal muscle precursor cells in vivo by use of MyoD1 and MyoG probes. Cell and Tissue Research. https://doi.org/10.1007/BF00318695
43. Chargé, S. B. P., \& Rudnicki, M. A. (2004). Cellular and molecular regulation of muscle regeneration. Physiological Reviews. https://doi.org/10.1152/physrev.00019.2003

44. Kharraz, Y., Guerra, J., Mann, C. J., Serrano, A. L., \& MuñozCánoves, P. (2013). Macrophage plasticity and the role of inflammation in skeletal muscle repair. Mediators of Inflammation. https://doi.org/10.1155/2013/491497

45. Teixeira, C. F. P., Zamuner, S. R., Zuliani, J. P., Fernandes, C. M., da Cruz-Höfling, M. A., Fernandes, I., Chaves, F., \& Gutiérrez, J. M. (2003). Neutrophils do not contribute to local tissue damage, but play a key role in skeletal muscle regeneration, in mice injected with Bothrops asper snake venom. Muscle and Nerve. https://doi.org/10.1002/mus.10453

46. Teixeira, C. F. P., Chaves, F., Zamunér, S. R., Fernandes, C. M., Zuliani, J. P., da Cruz-Höfling, M. A., Fernandes, I., \& Gutiérrez, J. M. (2005). Effects of neutrophil depletion in the local pathological alterations and muscle regeneration in mice injected with Bothrops jararaca snake venom. International Journal of Experimental Pathology. https://doi.org/10.1111/j. 0959-9673.2005.00419.x

47. Boeno, C. N., Paloschi, M. V., Lopes, J. A., Pires, W. L., Setúbal, S. S., Evangelista, J. R., Soares, A. M., \& Zuliani, J. P. (2020). Inflammasome activation induced by a snake venom Lys49-phospholipase $\mathrm{A}_{2}$ homologue. Toxins. https://doi.org/10. 3390/toxins12010022

48. Zheng, D., Liwinski, T., \& Elinav, E. (2020). Inflammasome activation and regulation: Toward a better understanding of complex mechanisms. Cell Discov. https://doi.org/10.1038/ s41421-020-0167-X

49. Gouveia, V. A., Pisete, F. R. F. S., Wagner, C. L. R., Dalboni, M. A., Oliveira, A. P. L., Cogo, J. C., \& Zamuner, S. R. (2020). Photobiomodulation reduces cell death and cytokine production in $\mathrm{C} 2 \mathrm{C} 12$ cells exposed to Bothrops venoms. Lasers in Medical Science. https://doi.org/10.1007/s10103-019-02884-4

50. Barbosa, A. M., Villaverde, A. B., Guimarães-Sousa, L., Soares, A. M., Zamunér, S. F., Cogo, J. C., \& Zamunér, S. R. (2010). Low-level laser therapy decreases local effects induced by myotoxins isolated from Bothrops jararacussu snake venom. Journal of Venomous Animals and Toxins Including Tropical Diseases. https://doi.org/10.1590/S1678-91992010000300014

51. Amorim, F. G., Costa, T. R., Baiwir, D., De Pauw, E., Quinton, L., \& Sampaio, S. V. (2018). Proteopeptidomic, functional and immunoreactivity characterization of Bothrops moojeni snake venom: Influence of snake gender on venom composition. Toxins (Basel). https://doi.org/10.3390/toxins 10050177

52. Assis, L., Moretti, A. I., Abrahão, T. B., de Souza, H. P., Hamblin, M. R., \& Parizotto, N. A. (2013). Low-level laser therapy $(808 \mathrm{~nm})$ contributes to muscle regeneration and prevents fibrosis in rat tibialis anterior muscle after cryolesion. Lasers in Medical Science. https://doi.org/10.1007/s10103-012-1183-3

53. Brunelli, R. M., Rodrigues, N. C., Ribeiro, D. A., Fernandes, K., Magri, A., Assis, L., Parizotto, N. A., Cliquet, A., Jr., Renno, A. C., \& Abreu, D. C. (2014). The effects of 780-nm low-level laser therapy on muscle healing process after cryolesion. Lasers in Medical Science. https://doi.org/10.1007/s10103-013-1277-6

54. Relaix, F., \& Zammit, P. S. (2012). Satellite cells are essential for skeletal muscle regeneration: The cell on the edge returns centre stage. Development. https://doi.org/10.1242/dev.069088

55. Kuang, S., \& Rudnicki, M. A. (2008). The emerging biology of satellite cells and their therapeutic potential. Trends in Molecular Medicine. https://doi.org/10.1016/j.molmed.2007.12.004

56. Tedesco, F. S., Dellavalle, A., Diaz-Manera, J., Messina, G., \& Cossu, G. (2010). Repairing skeletal muscle: Regenerative potential of skeletal muscle stem cells. The Journal of Clinical Investigation. https://doi.org/10.1172/JCI40373 
57. Sambasivan, R., \& Tajbakhsh, S. (2015). Adult skeletal muscle stem cells. Results and Problems in Cell Differentiation. https:// doi.org/10.1007/978-3-662-44608-9_9

58. Trajano, L. S., Stumbo, A. C., Silva, C. L., Mencalha, A. L., \& Fonseca, A. S. (2016). Low-level infrared laser modulates muscle repair and chromosome stabilization genes in myoblasts. Lasers in Medical Science. https://doi.org/10.1007/s10103-016-1956-1

59. Lepper, C., Conway, S. J., \& Fan, C. M. (2009). Adult satellite cells and embryonic muscle progenitors have distinct genetic requirements. Nature. https://doi.org/10.1038/nature08209

60. Ehrhardt, J., \& Morgan, J. (2005). Regenerative capacity of skeletal muscle. Current Opinion in Neurology. https://doi.org/10. 1097/01.wco.0000177382.62156.82

61. Shefer, G., Oron, U., Irintchev, A., Wernig, A., \& Halevy, O. (2001). Skeletal muscle cell activation by low-energy laser irradiation: A role for the MAPK/ERK pathway. Journal of Cellular Physiology. https://doi.org/10.1002/1097-4652(2001)9999:9999\% 3c::AID-JCP1053\%3e3.0.CO;2-9

62. Shefer, G., Partridge, T. A., Heslop, L., Gross, J. G., Oron, U., \& Halevy, O. (2002). Low-energy laser irradiation promotes the survival and cells cycle entry of skeletal muscle satellite cells. Journal of Cell Science, 115(7), 1461-1469 PMID: 11896194.

63. Füchtbauer, E. M., \& Westphal, H. (1992). MyoD and myogenin are coexpressed in regenerating skeletal muscle of the mouse. Developmental Dynamics. https://doi.org/10.1002/aja.10019 30106

64. Marsh, D. R., Criswell, D. S., Carson, J. A., \& Booth, F. W. (1997). Myogenic regulatory factors during regeneration of skeletal muscle in young, adult, and old rats. Journal of Applied Physiology. https://doi.org/10.1152/jappl.1997.83.4.1270

65. Mesquita-Ferrari, R. A., Alves, A. N., Cardoso, V. O., Artilheiro, P. P., Bussadori, S. K., Rocha, L. A., Nunes, F. D., \& Fernandes, K. P. S. (2015). Low-level laser irradiation modulates cell viability and creatine kinase activity in $\mathrm{C} 2 \mathrm{C} 12$ muscle cells during the differentiation process. Lasers in Medical Science. https://doi.org/10. 1007/s10103-015-1715-8

66. Silva, L. M. G., Silva, C. A. A., Silva, A., Vieira, R. P., MesquitaFerrari, R. A., Cogo, J. C., \& Zamunér, S. R. (2016). Photobiomodulation protects and promotes differentiation of $\mathrm{C} 2 \mathrm{C} 12$ myoblast cells exposed to snake venom. PLoS ONE. https://doi.org/ 10.1371/journal.pone. 0152890
67. Blais, A., Tsikitis, M., Acosta-Alvear, D., Sharan, R., Kluger, Y., \& Dynlacht, B. D. (2005). An initial blueprint for myogenic differentiation. Genes and Development. https://doi.org/10.1101/gad. 1281105

68. Alves, A. N., Ribeiro, B. G., Fernandes, K. P. S., Souza, N. H. C., Rocha, L. A., Nunes, F. D., Bussadori, S. K., \& Mesquita-Ferrari, R. A. (2016). Comparative effects of low-level laser therapy preand post-injury on mRNA expression of MyoD, myogenin, and IL-6 during the skeletal muscle repair. Lasers in Medical Science. https://doi.org/10.1007/s10103-016-1908-9

69. Huang, Y.-Y., Sharma, S. K., Carroll, J., \& Hamblin, M. R. (2011). Biphasic dose response in low level light therapy-An update. Dose Response. https://doi.org/10.2203/dose-response.11-009. Hamblin

70. Khacho, M., \& Slack, R. S. (2017). Mitochondrial activity in the regulation of stem cell self-renewal and differentiation. Current Opinion in Cell Biology. https://doi.org/10.1016/j.ceb.2017.11. 003

71. Xu, X., Duan, S., Yi, F., Ocampo, A., Liu, G.-H., \& Belmonte, J. C. I. (2013). Mitochondrial regulation in pluripotent stem cells. Cell Metabolism. https://doi.org/10.1016/j.cmet.2013.06.005

72. Karu, T. I. (2008). Mitochondrial signaling in mammalian cells activated by red and near-IR radiation. Photochemistry and Photobiology. https://doi.org/10.1111/j.1751-1097.2008.00394.x

73. Koch, S., Tugues, S., Li, X., Gualandi, L., \& Claesson-Welsh, L. (2011). Signal transduction by vascular endothelial growth receptors. Biochem. https://doi.org/10.1042/BJ20110301

74. Germani, A., Di Carlo, A., Mangoni, A., Straino, S., Giacinti, C., Turrini, P., Biglioli, P., \& Capogrossi, M. C. (2003). Vascular endothelial growth factor modulates skeletal myoblast function. American Journal of Pathology. https://doi.org/10.1016/S00029440(10)63499-2

75. Dourado, D. M., Fávero, S., Matias, R., Carvalho, P. T. C., \& da Cruz-Höfling, M. A. (2011). Low-level laser therapy promotes vascular endothelial growth factor receptor-1 expression in endothelial and nonendothelial cells of mice gastrocnemius exposed to snake venom. Photochemistry and Photobiology. https://doi.org/10.1111/j.1751-1097.2010.00878.x 